\title{
Intractable Central Pain in Spinal Cord Injury is not Relieved by Spinal Cord Stimulation
}

\author{
J. D. Cole, MA, MSc, DM, MRCP, L. S. Illis, BSc, MD, FRCP, \\ E. M. Sedgwick, BSc, MD \\ Wessex Neurological Centre, Southampton General Hospital, Southampton, S09 4XY, \\ $U K$.
}

\begin{abstract}
Summary
The results from a trial of spinal cord stimulation (SCS) for intractable deafferentation pain in chronic spinal cord injury is presented. Adequate periods of SCS both above and below the level of the lesion had no effect on the subjects' pain. It is concluded that SCS has no role in this group of patients. The physiological reason for this ineffectiveness is considered.
\end{abstract}

Key words: Deafferentiated intractable pain; Spinal cord injury; Spinal cord stimulation.

One of the most debilitating consequences of spinal cord injury, (SCI), is chronic pain. Although often at a relatively bearable intensity it can limit work, social activities and sleep in over a quarter of the chronically injured, (Rose, Robinson, Ells and Cole, 1988). Pain in subjects with spinal injury may be divided into five types: (a) root pain; (b) visceral pain, (often accompanying distension of the bladder or bowel); (c) musculoskeletal pain; and (d) late pain associated with syringomyelia and (e) phantom body pain, (Guttmann, 1973; Melzack and Loeser, 1978). Beric, (1990), distinguished between SCI related pain, e.g. (a) and (b) above, and SCI pain itself. Phantom body pain is felt in the area of complete sensory loss and so may be termed a central deafferentation pain.

Spinal cord stimulation, (SCS), has been found to be effective in several groups of patients. It can relieve spasticity, (Dimitrijevic et al., 1986; Dimitrijevic and Illis, 1986), improve bladder control and relieve the pain in multiple sclerosis, (Cook and Weinstein, 1973; Illis, 1976; Illis, 1980), and has proved effective in relieving peripheral vascular disease, (Tallis, 1983). Lastly in some painful deafferentation syndromes, for instance, phantom limb pain, SCS has proved

Correspondence to: Dr J. D. Cole, Wessex Neurological Centre, Southampton General Hospital, Southampton, SO9 4XY, UK. 
reasonably successful for varying lengths of time, (Krainick 1980). It therefore seemed logical to assess its usefulness in SCI in which pain is also associated with deafferentation.

\section{Methods}

The technique of SCS has been extensively described elsewhere, (Cook, 1973; Illis et al., 1976). In Southampton patients are placed prone on an X-ray screening tube and under local anaesthesia a Medtronic electrode is introduced into the epidural space under X-ray control. It is advanced gently up the space until its tip is several segments rostrally overlying the spinal cord. It is then connected to a power source with the earth pad placed in a convenient position on the skin. The patient is asked what they feel and the best position is that there should be a warm tingling sensation going down into the legs. The patient is then allowed to control the rate, (between 10 and $100 \mathrm{~Hz}$ ), the amplitude of the current, (1-10 mA), and the duration of each pulse, (10-100 us), themself and is encouraged to experiment to optimise the response.

The temporary electrode passes out of the skin and is covered in dressings. After a suitable period, if considered effective, the whole system can be made internal by connecting the electrode with a subcutaneous receiver operated by an ariel placed overlying the receiver over the skin. If no effect is found within a reasonable period between one week to a month or so then the electrode is removed. The procedure has been passed by local hospital ethical committees and each patient's informed written consent is gained.

\section{Patients}

The procedure was tried on 4 patients with intractable central deafferentation pain following SCI.

Subject 1 was a 26-year-old man with a clinically complete T9-T10 lesion following a road traffic accident 2 years previously. His pain had begun 2 weeks after the injury and initially was in the feet and described as being intermittent. Slowly it had spread to cover the scrotum and rectum. Although there was a day to day variation on a bad day it became intolerably sharp and even at its least was a dull pins and needles pain. It continued to worsen in the year before he was seen. He had tried Distalgesic, DF 188 and Temgesic without effect. On examination he had a complete sensory lesion at T9 on the left and T10 on the right. No movement was possible below the lesion, the legs were extremely spastic with frequent flexor and adductor spasm.

Subject 2: A 43-year-old man with a T11/12 injury for last 16 years. Since the injury he has had no movement, no sensation and no continence below the injury. His pain had begun a few months after the injury and was localised to the back, buttocks and across the thighs to reach the knee. Initially it had been present on alternate days but had soon become more persistent. He described it as being on an analogue scale 7 out of 10 for $95 \%$ of the time and 9 out of 10 for $5 \%$ of the time. He had tried DF 118 and Temgesic. On examination he had a T8 lesion on the right, T6 on the left to all sensory modalities. There was no movement and no reflexes in the legs. 
Subject 3: A 70-year-old woman who had had a bleed from an A-V malformation 10 years previously. This had left her paraplegic and asensatient from T11 downwards. Four months after the bleed she had first noticed pain in her vagina and rectum and right leg. Since then it had increased and been constant. Sleep was possible only with Nitrazepam but was interrupted several times a night. She has tried DF 118, Paracetamol, Distalgesic, Carbamazepam, Diazepam, Prothiadin and Chlorpromazine. On examination the lower abdominal reflexes were absent and in her legs she showed wasting, no movement and flaccid tone. The tendon jerks were absent except for right ankle jerk which was present with clonus. All sensory modalities were absent below T12.

Subject 4: A 41-year-old woman who 3 years earlier had had a thoracic SCI secondary to a road traffic accident. Since then she had had no movement or sensation in the legs. The pain had begun a few weeks after her injury. She described it as occasionally sharp and stabbing but present to some extent all the time. She had tried Paracetamol, Omnopon, Carbamazepine and had had paravertebral blocks without effect. On examination her legs were flaccid in tone with no movement and no reflexes. There was absence of sensation in the legs.

\section{Results}

The number and effect of SCS procedures are shown in abbreviated form in the Table.

In subject 1 an epidural electrode was positioned at T7 in the midline for 3 days giving continuous stimulation which was felt in the T6/7 dermatome in the area of the ribs. Despite several attempts at moving the electrode no sensation could be felt

Table Summary of the spinal cord stimulation procedures

\begin{tabular}{|c|c|c|c|c|c|c|}
\hline Patient & $\begin{array}{l}\text { Site of } \\
\text { lesion }\end{array}$ & $\begin{array}{l}\text { Site of } \\
\text { electrode }\end{array}$ & $\begin{array}{l}\text { Stimulator } \\
\text { sensation }\end{array}$ & $\begin{array}{l}\text { Duration of } \\
\text { stimulation }\end{array}$ & $\begin{array}{l}\text { Effect on } \\
\text { pain }\end{array}$ & $\begin{array}{l}\text { Other } \\
\text { effects }\end{array}$ \\
\hline \multirow[t]{5}{*}{ ME 487} & $\mathrm{~T} 9 / 10$ & T3-earth & $\begin{array}{l}\mathrm{T} 3 / 5 \\
\text { dermatome }\end{array}$ & 3 days & Nil & None \\
\hline & & L1-earth & Nil & 3 days & Nil & $\begin{array}{l}\text { Movement if } \\
\text { stimulation } \\
\text { high }\end{array}$ \\
\hline & & T3-L1 & Nil & & Nil & Movement \\
\hline & & T5-earth & $\begin{array}{l}\text { Dermatomal } \\
\text { T8 }\end{array}$ & 7 days & Nil & None \\
\hline & & T10-earth & Nil & 7 days & Nil & Movement \\
\hline \multirow[t]{2}{*}{ KF 395} & $\mathrm{~T} 11 / 12$ & T6 & Dermatome & 3 days & Nil & None \\
\hline & & $\mathrm{T} 7$ & Dermatome & 1 day & Nil & None \\
\hline \multirow[t]{4}{*}{ EN 561} & $\mathrm{~T} 12$ & T5 & $\begin{array}{l}\text { Dermatomal } \\
\text { ?vaginal }\end{array}$ & 2 days & Nil & None \\
\hline & & T8 & Dermatomal & 3 days & Nil & None \\
\hline & & $\mathrm{T} 4$ & Dermatomal & 5 days & Nil & None \\
\hline & & L1/T12 & $\begin{array}{l}\text { Vagina low } \\
\text { abdomen } \\
\text { initially } \\
\text { nil }\end{array}$ & 6 days & $\begin{array}{l}\text { No signi- } \\
\text { ficant } \\
\text { effect }\end{array}$ & $\begin{array}{l}\text { Movement of } \\
\text { stimulation }\end{array}$ \\
\hline \multirow[t]{2}{*}{ JH 56160} & $\mathrm{~T} 12 / \mathrm{L} 1$ & T3 & Dermatomal & 6 days & Nil & None \\
\hline & & T5 & Dermatomal & 8 days & Nil & \\
\hline
\end{tabular}


below the level of the lesion. The stimulator sensation was separate to and had no effect on the pain. It was subsequently removed.

Two spinal cord stimulating electrodes were inserted into Subject 2. The first through the T7/8 intervertebral space and it was passed to T3 level. The second through the L1/T12 space and this was positioned at T12 level. The first electrode, when stimulated and connected to the surface earth gave sensation in the low back area but no sensation in the painful area. The second electrode produced no sensation before the activation of motor neurons leading to twitching of the legs. When the electrodes were connected to each other there was no sensation before reaching threshold for muscular twitch. No effect on pain was felt despite 4 days of trial.

A second set of electrodes was tried, a rostral one at T5 and a caudal one at T10. Once more stimulation of the caudal one below the level of the lesion produced only twitch movement and no sensation. The T5 electrode gave sensation in a T8-9 distribution, suggesting that it was in a good midline position and giving projected sensation. However this sensation did not go down below the level of the lesion and had no effect on the pain. Two weeks trial of various electrode configuration had no effect on the pain, there having been no overlap of the projected area and sensation and the painful area itself.

In Subject 3 electrodes were placed at the T5 level through the T8/9 interspace. Whilst this was being done she claimed vaginal sensation but this could not be sustained and she was left with sensation only in the T5 segmental distribution. Positioning the second electrode at T8 just above her lesion gave some projected sensation into the legs and vagina but this position was too close to the site of insertion of the electrode for it to be maintained. A further insertion and positioning of the electrode at the $\mathrm{T} 4$ level gave sensation in the legs but no analgesic effect was reported after several days trial. This was an interesting situation because she claimed to be perceiving some sensation below what was apparently a clinically complete lesion. In view of this it was decided to try SCS below her lesion and an electrode was passed through the L3/4 space and threaded rostrally to the T12 level. Stimulation there produced some sensation in both rectum and vagina but again this was not sustained and after 3 days of stimulation had had no effect on her pain and so it was withdrawn.

Subject 4 had had an internal fixation of her mid-thoracic vertebral fracture and so it was necessary to pass the electrode rostrally at around T7 and advance it to T3 level before stimulation. At this level she had sensation in the chest on both sides and at the base of the spine but no projection into the legs and no overlap of the stimulator and pain sensations. Initially the patient thought her pain had been reduced but this was not a sustained change and so the electrode was removed. After a short period she returned for a second trial of spinal cord stimulation when an electrode was introduced at the same place. Once more she initially thought it was relieving the pain but over the next few days the pain returned and so after a week of stimulation the electrode was withdrawn and the trial discontinued.

\section{Discussion}

The main finding from the study is that SCS is not an effective technique for the relief of chronic deafferentation pain projected below the level of complete SCI. 
Richardson (1980), found similar results in a series of 10 paraplegics with intractable pain. Their sample included 4 subjects with incomplete lesions, (presumably on clinical grounds), and 6 with central pain, 1 with radicular pain and 3 with visceral pain. Their work together with the present results do not make a large sample, but the complete absence of any analgesic effect would seem convincing. This is in contrast to its proven effectiveness in some other pain syndromes. The reason for this will be considered.

In other deafferentation pain syndromes SCS is only effective when the projected sensation from stimulation is felt in the painful area, (for review see Krainick and Thoden, 1989). In phantom limb pain, when damage has occurred to a peripheral nerve, stimulation of dorsal column afferents in the spinal cord can still lead to this. However the intractable pain considered in the present paper was projected below the level of the lesion rather than being in a root distribution in subjects with complete SCI.

The intractable pain is likely to arise centrally although its exact site or site of origin is not known. It has been considered to arise from the damaged remnant of the spinal cord stump, (Holmes, 1917). Against that, however, Melzack and Loeser, (1978), have described several patients in whom this pain was not permanently relieved by complete cord transection. As they discuss, deafferentation pain may be a result of complex reorganisation within the central nervous system at levels above the cord even though the initial stimulus leading to pain was related to the cord injury. Richardson et al. also suggested that their failure to alleviate pain could have been due to the fact that the abnormal pain producing cells were rostral to the site of stimulation.

In peripheral deafferentation pain spinal cord stimulation probably works by an effect via dorsal column afferents' collaterals on spinothalamic tract cells in the dorsal horn. If these dorsal column afferents are absent, because they have been destroyed by the spinal injury, the effect can no longer be produced. If spinal deafferentation pain arises centrally then this absence of dorsal column afferents makes SCS less likely to be useful on theoretical grounds.

Despite the apparent logic of attempting SCS in the deafferentation pain of spinal cord injury, because it had been successful in other deafferentation pains, it is an illogical technique physiologically. The failure to produce any clinical benefit from SCS in intractable pain of SCI may not therefore have been a surprise. With no clinical benefit and a sound physiological reason for the failure, it is concluded that SCS has no role in pain control in intractable deafferentation pain following SCI.

\section{Acknowledgements}

J. D. Cole was an International Spinal Research Trust Fellow during this study.

\section{References}

BERIC A 1990 In Spinal Cord Dysfunction II Ed. L. S. Illis, Oxford University Press, (In press). COOK AW, WEINSTEIN SP 1973 Chronic dorsal column stimulation in multiple sclerosis, Preliminary report, New York State fournal of Medicine 73:2868-2872.

Dimitrijevic MM, Dimitrijevic MR, Illis LS, Nakajima K, Sharkey PC, Sherwood AM 1986 Spinal cord stimulation for the control of spasticity in patients with chronic spinal cord injury. I. Clinical observations. Central Nervous System and Trauma 3:129-144. 
Dimitrijevic MR, Illis LS, Nakajima K, Sharkey PC, Sherwood AM 1986 Spinal cord stimulation for the control of spasticity in patients with chronic spinal cord injury. II. Neurophysiological observations. Central Nervous System and Trauma 3:145-152.

Guttmann L 1973 Spinal Injuries: Comprehensive Management and Research, Blackwell, Oxford.

Holmes G 1917 Pain of Central Origin. In: Contributions to medical and biological research, dedicated to Sir William Osler, New York 1: 235.

Illis LS, Sedgwick EM, OgYar AE, Awadalla MAS 1976 Dorsal column stimulation in the rehabilitation of patients with multiple sclerosis, Lancet i:1383-6.

ILLIS LS, SEDGWICK EM, TALLIS RC 1980 Spinal cord stimulation in multiple sclerosis: clinical results. Fournal of Neurology, Neurosurgery and Psychiatry 43:1-14.

KraINICK J-U, ThODEN U 1989 Dorsal Column Stimulation. In: Wall PD and Melzack R Textbook of Pain, Churchill Livingstone, Edinburgh, 920-924.

KRAINICK J-U, THODEN U, RIEChERT T 1980 Pain reduction in amputees by long-term spinal cord stimulation. Fournal of Neurosurgery 52:346-350.

MELZACK R, LOESER JD 1978 Phantom body pain in paraplegics: evidence for a central 'pattern generating mechanism' for pain. Pain 4:195-210.

RICHARDSON RR, MEYER PR, CERULlo LJ 1980 Neurostimulation in the modulation of intractable paraplegic and traumatic neuroma pains. Pain 8:75-84.

Rose M, RoBINSON JE, Ells P, COLE JD 1988 Pain following spinal cord injury: results from a postal survey. Pain 34:101-102.

Tallis RC, Illis LS, SEDGWICK EM, GaRfIELd JS 1983 Spinal cord stimulation in peripheral vascular disease. Fournal of Neurology, Neurosurgery and Psychiatry 46:478-484. 